\title{
Awareness of Different Forms of Denture Adhesives Among Dental Students
}

\author{
Keerthana Baskar ${ }^{1}$ and Suresh Venugopalan ${ }^{2}$ \\ ${ }^{1}$ Saveetha Dental College and Hospitals, Saveetha Institute of Medical \\ and Technical Sciences, Saveetha University, Chennai,India \\ ${ }^{2}$ Reader, Department of Prosthodontics, Saveetha Dental College and Hospitals, Saveetha \\ Institute of Medical and Technical Sciences, Saveetha University, Chennai,India
}

\section{ABSTRACT}

Complete dentures constitute one of the most important treatment options in prosthodontics. Denture adhesives seem to improve oral health related quality of life of patients with edentulism. The aim of the study is to evaluate the knowledge, awareness and perception of denture adhesive among dental students. A cross-sectional study was conducted among 150 dental students belonging to third year, final year and internship selected by simple random sampling. The questionnaire was pre-fabricated , simple, close-ended. Data was gathered using an online survey application. It has been observed that all the interns and majority of third year students and final year students were aware of denture adhesives. Only $8 \%$ of third year students, $13.3 \%$ of final year students and 6.6\% of interns do not use denture adhesives in the present study. Within the limitations of the study, it has been studied that most of the undergraduate dental students were aware of the denture adhesives that are being used although majority of the students were not aware of the different forms of available denture adhesives.

KEY WORDS: DENTURE; ADHESIVE; RETENTION; STABILITY.

\section{INTRODUCTION}

Complete dentures constitute one of the most important treatment options in prosthodontics, more so with an increase in average life expectancy of the individual. Newly made dentures could be a disappointment to a patient if deficient in retention and/or stability and could contribute to a sense of social anxiety and lack of confidence in them . However, retention of complete dentures has always posed to be a problem for the dentist

\section{ARTICLE INFORMATION}

*Corresponding Author: suresh@saveetha.com

Received 15th June 2020 Accepted after revision 3rd August 2020

Print ISSN: 0974-6455 Online ISSN: 2321-4007 CODEN: BBRCBA

Thomson Reuters ISI Web of Science Clarivate Analytics USA and Crossref Indexed Journal

\section{Clarivate
Analytics}

NAAS Journal Score 2020 (4.31) SJIF: 2020 (7.728)

A Society of Science and Nature Publication,

Bhopal India 2020. All rights reserved.

Online Contents Available at: http//www.bbrc.in/

Doi: $h t t p: / / d x$.doi.org/10.21786/bbrc/13.7/45
(Mantri et al., 2014). Denture adhesives (DA), also referred to as adherents or fixatives, have long been recognized by denture wearers as a useful adjunct to denture retention, stability, and function. (Grasso, 2004) Denture adhesives enhance the retention, stability, masticatory performance, occlusal force, sealing out of food particles, and overall function of dentures. In addition, Denture adhesives seem to improve oral health related quality of life of patients with edentulism. (Polyzois et al., 2017) Overall, the use of Denture adhesives has been an intriguing and controversial topic in both clinical practice and in academia.

The conflicting viewpoints among dental professionals can be described as the traditional historical and the advocate approaches. Denture adhesives have a profound place in prosthetic dental treatment but often dentists do not prescribe them for fear that it indicates their failure to provide a fitting prosthesis.(Shah et al., 2015) Many dentists also fear that DAs are causing increased residual 
ridge resorption (RRR) and soft tissue hyperplasia (Neill and Roberts, 1973; Karlsson and Swartz, 1981) Studies show that denture adhesives when properly used provide and benefit denture patients with improved fit, comfort, chewing ability and confidence . (Figueiral et al., 2011; Ahlawat et al., 2012; Gonçalves et al., 2014) The use of denture adhesives in complete dentures can be justified when it is not possible to obtain sufficient retention and stability and when implants or surgical ridge augmentation procedures are not an option because of the patient's economic situation, systemic conditions, or age (Musani, Dugal and Kothavade, 2010; Shah, 2012).

The conflicting viewpoints among dental professionals have led to slow acceptance of Denture adhesives in their practice as a means to enhance denture retention, stability and function. Dentists need to be familiar with Denture adhesives to be able identify those patients who actually need them and to be able to educate them about the advantages, disadvantages and correct use of these products. This is an intriguing topic because it has received so little attention in the formal training of dentists, despite their widespread use among denture wearers. Previously our department has published extensive research on various aspects of prosthetic dentistry ('Evaluation of Corrosive Behavior of Four Nickel-chromium Alloys in Artificial Saliva by Cyclic Polarization Test:An in vitro Study', 2017; Ganapathy, Kannan and Venugopalan, 2017; Jain, 2017a, 2017b; Ranganathan, Ganapathy and Jain, 2017; Ariga et al., 2018; Gupta, Ariga and Deogade, 2018; Anbu et al., 2019; Ashok and Ganapathy, 2019; Duraisamy et al., 2019; Varghese, Ramesh and Veeraiyan, 2019), this vast research experience has inspired us to research about the knowledge,awareness and perceptions of different forms of denture adhesives among dental students.

\section{MATERIAL AND METHODS}

Data collection: A cross sectional study was conducted in January 2020 among dental undergraduates (Third years, Final years, Interns). It was an online questionnaire based study, conducted to assess the knowledge, attitude and awareness on the management of the maxillary antrum carcinomas. 150 dental undergraduates (Third years, Final years, Interns) participated in this study. The data collection was done via google forms.

Survey instrument: A pretested, self administered, closed ended questionnaire comprising the following sections formed the survey instrument. A structured questionnaire containing 10 questions which was adopted from a validated questionnaire developed by the World Health Organisation.The goal of developing this questionnaire was to know about the knowledge, awareness and perception the dental undergraduates had on denture adhesives.

Data analysis: The data collected was entered in an Excel sheet and subjected to statistical analysis using SPSS software. Chi square test was done. The independent variables are age and gender while dependent variables are knowledge,attitude and awareness on the different forms of denture adhesive among dental students. The level of significance was set at $\mathrm{p}<0.05$.

\section{RESULTS AND DISCUSSION}

In this study, it has been observed that all the interns and majority of third year students and final year students were aware of denture adhesives (Figure 1). Only 8\% of third year students, $13.3 \%$ of final year students and 6.6\% of interns do not use denture adhesives in the present study (Figure 2). Most of the dental students responded that the denture adhesive enhances the stability and retention of the prosthesis (Figure 3). 26.6\% of third year students, $26.6 \%$ of final year students and $24 \%$ of interns felt that DA provide psychological comfort to the patients (Figure 4). 4.6\% of third year students, 12\% of final year students and 9.3\% of interns felt that the use of DA encourages improper practical use (Figure 5).

Figure 1: Bar graph depicts the association between the year of study of the participants and their awareness on denture adhesives. $\mathrm{X}$ axis denotes the year of study of participants and $\mathrm{Y}$ axis denotes the number of students. Majority of the participants have given a response of yes(blue). Chi square test was done and $\mathrm{p}$ value was found to be 0.000 hence statistically significant.

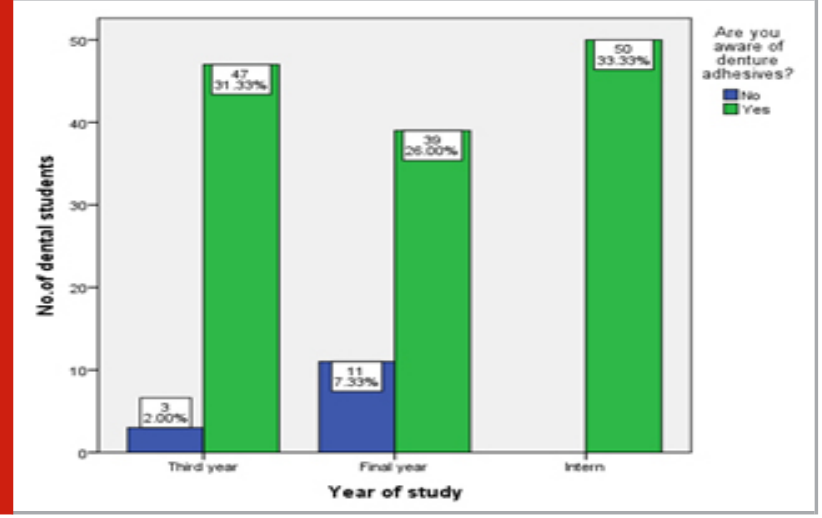

Figure 2: Bar graph depicts the association between year of study of the participants and if denture adhesives are used in the practise. $\mathrm{X}$ axis denotes the year of study of participants and $\mathrm{Y}$ axis denotes the number of students. Majority of the participants have given a response of yes(green). Chi square test was done and $\mathrm{p}$ value was found to be 0.062 , hence statistically significant.

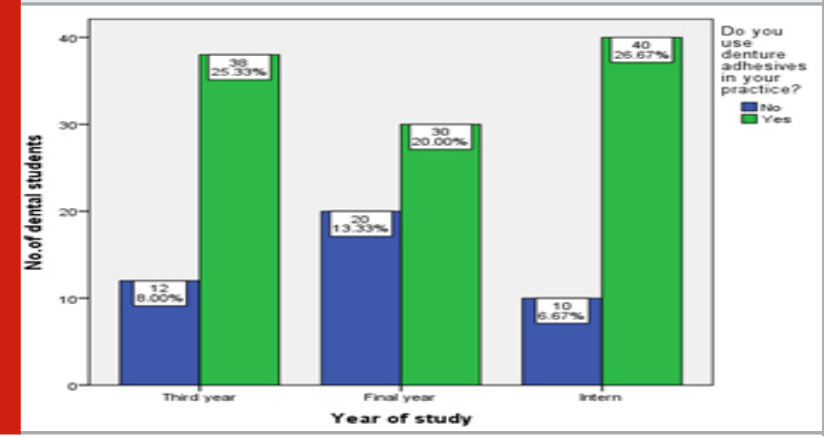


Figure 3: Bar graph depicts the association between the year of study of the participants and knowledge on stability and retention of the denture when DA is used. $\mathrm{X}$ axis denotes the year of study of participants and $\mathrm{Y}$ axis denotes the number of students. Majority of the participants have given a response of yes(green). Chi square test was done and $p$ value was found to be 0.000 hence statistically significant.

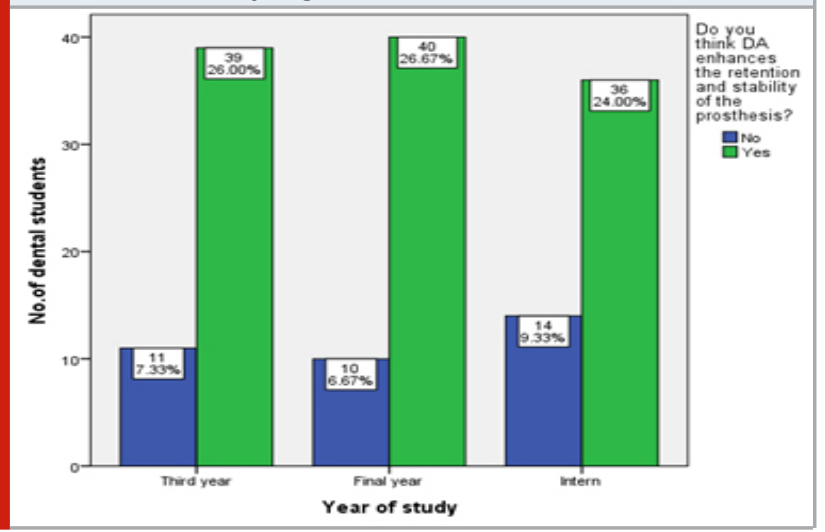

Figure 4: Bar graph depicts the association between years of study of the participants and if the DA provides psychological comfort to the patient. $\mathrm{X}$ axis denotes the year of study of participants and $Y$ axis denotes the number of students. Majority of the participants have given a response of yes(green). Chi square test was done and $\mathrm{p}$ value was found to be 0.002 hence statistically significant.

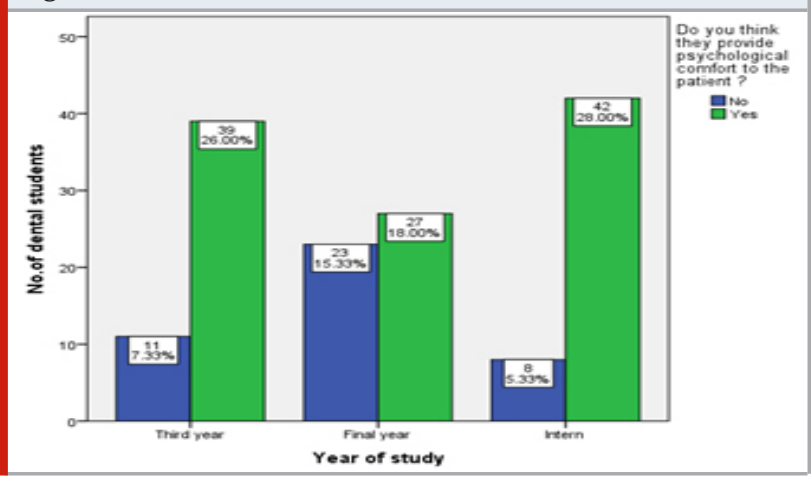

It has been observed that all the third year students were aware of only powder form of Denture Adhesive , 7.3\% of final year students used paste form and 4\% used strip form. Among interns, the majority used powder form while $12.6 \%$ used paste form and 2\% used strip form (Figure 6). All the interns felt that the use of DA drastically improved the quality in upper arch while only $20.6 \%$ of final year students and $12.3 \%$ of third year students felt the same (Figure 7). Regarding the retention in lower arch, 20.6\% of final year students and interns felt that the retention improves and 22\% of third year students felt the same (Figure 8).

Only 7.3\% $\%$ of interns, $6.7 \%$ of final year students and $13.3 \%$ of third year students had patients complaining about loss of retention even after using DA (Figure 9). $2.6 \%$ of final year students and 3.3\% of interns had patients who reported with a change in the type of DA being comfortable or uncomfortable (Figure 10). Majority of students did not know of patients using DA for a very long time (Figure 11). 5.3\% of final year students and $10 \%$ of interns had checked for retention with different types of adhesives (Figure 12)

Figure 5: Bar graph depicts the association between year of study of the participants and perspective of DA encouraging improper clinical practice. $\mathrm{X}$ axis denotes the year of study of participants and Y axis denotes the number of students. Majority of the participants have given a response of no(blue). Chi square test was done and $\mathrm{p}$ value was found to be 0.040 hence statistically significant.

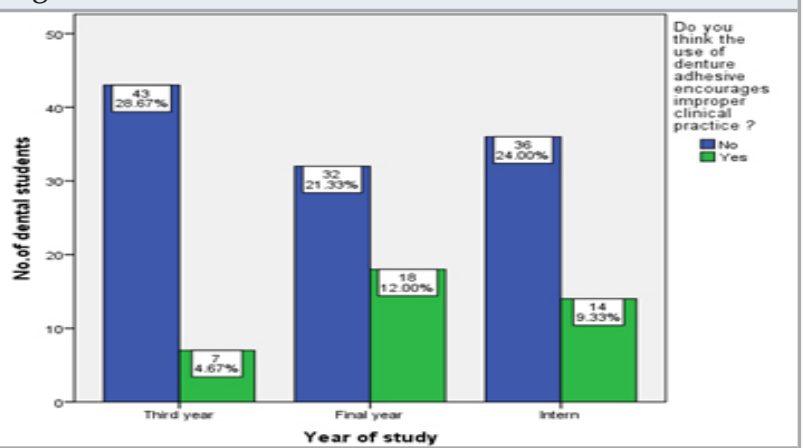

Figure 6: Bar graph depicts the association between year of study of the participants and perspective on type of denture adhesives. $\mathrm{X}$ axis denotes the year of study of participants and $\mathrm{Y}$ axis denotes the number of students. Majority of the participants have used powder form (purple), compared to paste( pink) and strips (brown). Chi square test was done and $p$ value was found to be 0.000 hence statistically significant.

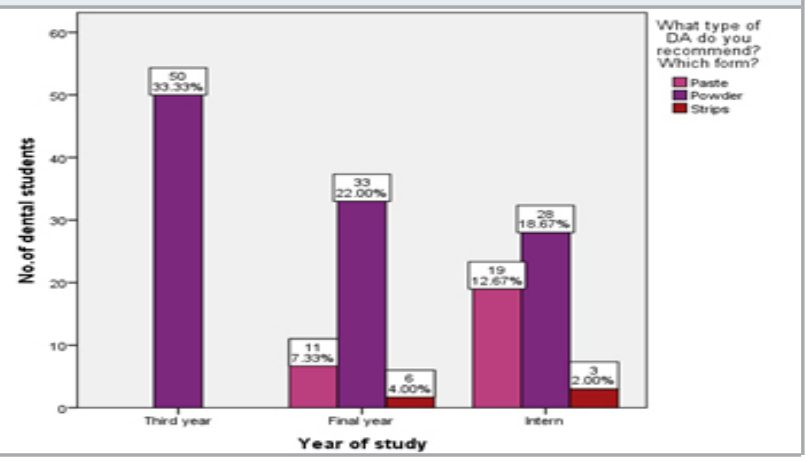

Studies showed that 40-60\% of the patients were not aware of denture adhesives which was significantly higher compared to the present study (Fakhri et al., 2009; Muneer, Ahmed and Kamran, 2013; Polyzois et al., 2017). In a study conducted by Polyzois et al, it has been found that $60.3 \%$ of dental practitioners recommended the use of denture adhesives, while another study showed that $80.3 \%$ of dental practitioners recommended the same. (Mantri et al., 2014; Polyzois et al., 2017) These results are in accordance with the present study. In a study 
conducted by Temel et al, it was reported that $81.2 \%$ of all respondents felt that the DAs may create problems with the oral mucosa. (Temel, 2007) In a study conducted by Polyzois et al, most (93.8\%) of them recommended cream form whereas in the present study powder form was used most commonly (74\%) (Polyzois et al., 2017).

Figure 7: Bar graph depicts the association between year of study of the participants and perspective on denture retention in upper arch using denture adhesives. $\mathrm{X}$ axis denotes the year of study of participants and $\mathrm{Y}$ axis denotes the number of students. Majority of the participants have given a response of yes(green), while many third years answered no (blue). Chi square test was done and $p$ value was found to be 0.000 hence statistically significant.

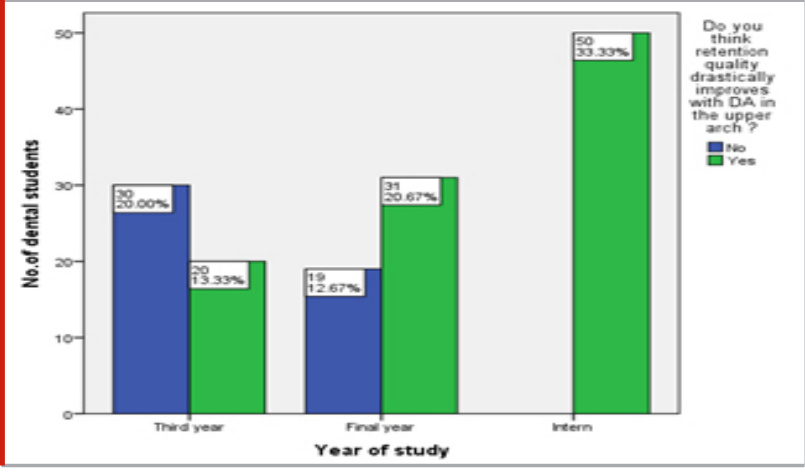

Figure 8: Bar graph depicts the association between year of study of the participants and perspective on denture retention in lower arch using denture adhesives. $\mathrm{X}$ axis denotes the year of study of participants and $\mathrm{Y}$ axis denotes the number of students. Majority of the participants have given a response of yes(green). Chi square test was done and $p$ value was found to be 0.000 hence statistically significant.

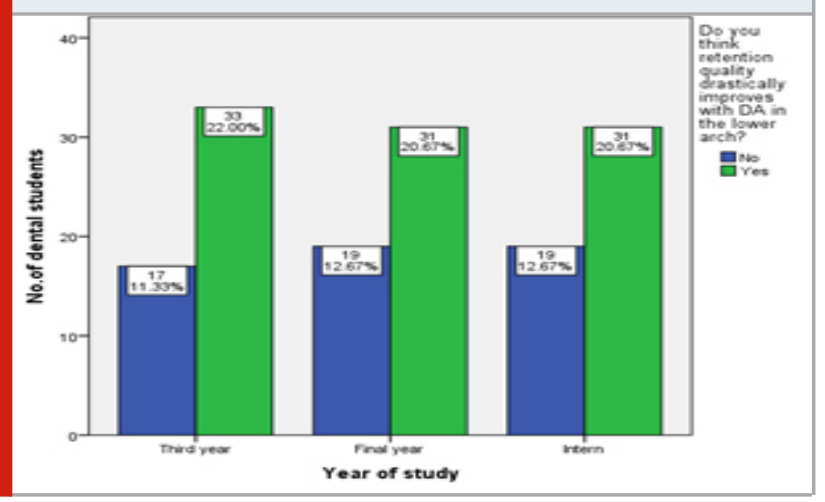

In a similar survey by Coates et al, 57.9\% had tried powder adhesive and $42.1 \%$ had tried paste adhesive (Coates, 2000)In the current study, 72\% of the students use denture adhesive which is well above the percentage recorded by Temel and mantri (Temel, 2007; Mantri et al., 2014). From the 318 denture adhesives users in a study conducted by Bo et al, 212(66.7\%) used cream; 74(23.3\%) used home liner; 25(7.9\%) used powder; $4(1.3 \%)$ used sheet; 3(0.9\%) used several types (Bo et al., no date) .
$57.21 \%$ of dentists used DAs as they improved fitness and $77.83 \%$ felt it provided a psychological comfort to the patient in a study conducted by Shah et al.) (Shah et al., 2015). Similar results were obtained in the present study.

Figure 9: Bar graph depicts the association between year of study of the participants and awareness on patients complaining of loss of retention. $\mathrm{X}$ axis denotes the year of study of participants and $\mathrm{Y}$ axis denotes the number of students. Majority of the participants have given a response of no (blue). Chi square test was done and $p$ value was found to be $\mathbf{0 . 0 0 0}$ hence statistically significant.

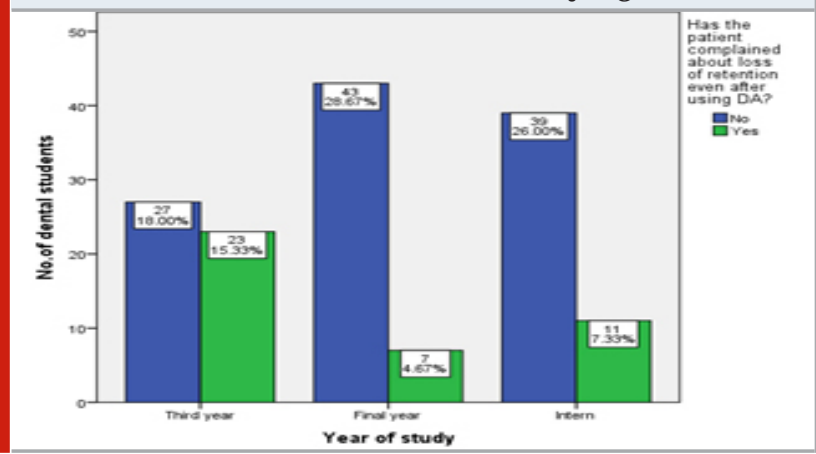

Figure 10: Bar graph depicts the association between the year of study of the participants and knowledge of patient reporting with change in comfortability with different types of DA. X axis denotes the year of study of participants and $\mathrm{Y}$ axis denotes the number of students. Majority of the participants have given a response of no (blue) . Chi square test was done and p value was found to be 0.001 hence statistically significant.

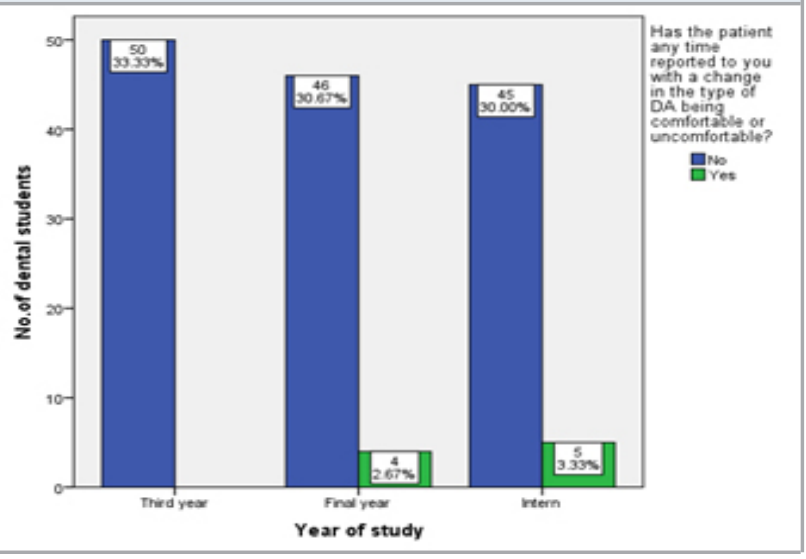

In our study it was found that the majority of the students felt that the retention of the prosthesis in the upper and lower was improved drastically when a denture adhesive was used. Very few students had complaints from patients for retention even after the use of DA in the present study similar results were obtained by (Coates, 2000). In our study, only $36.7 \%$ of students had patients who had been denture wearers for a very long time. While Coates stated that $54.9 \%$ of the patients wore denture for 10 years or more and 17.8\% had prosthesis for more 
than 20 years which is not in accordance with the present study. (Coates, 2000)

It is also important to note that patients should be educated about the importance of regular 'recall appointments' for the evaluation of the condition of denture and its foundation. These considerations are particularly important for patients employing DA because the use of products such as these can modify or eliminate customary cues for returning to the dental office.

Figure 11: Bar graph depicts the association between the year of study of the participants and knowledge of any patient using DA for a very long time. $\mathrm{X}$ axis denotes the year of study of participants and $Y$ axis denotes the number of students. Majority of the participants have given a no (blue). Chi square test was done and $p$ value was found to be 0.084 hence statistically significant.

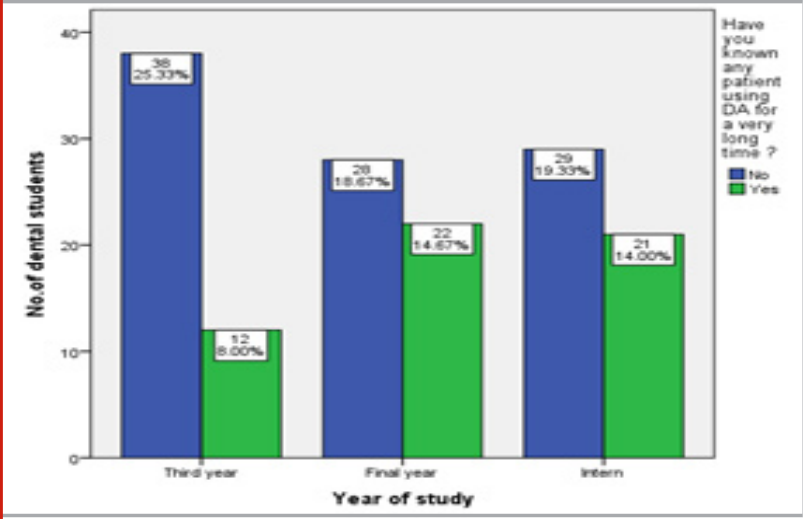

Figure 12: Bar graph depicts the association between the year of study of the participants and knowledge on retention with different types of DA. $\mathrm{X}$ axis denotes the year of study of participants and $Y$ axis denotes the number of students. Majority of the participants have given a response of no (blue) . Chi square test was done and $p$ value was found to be 0.001 hence statistically significant.

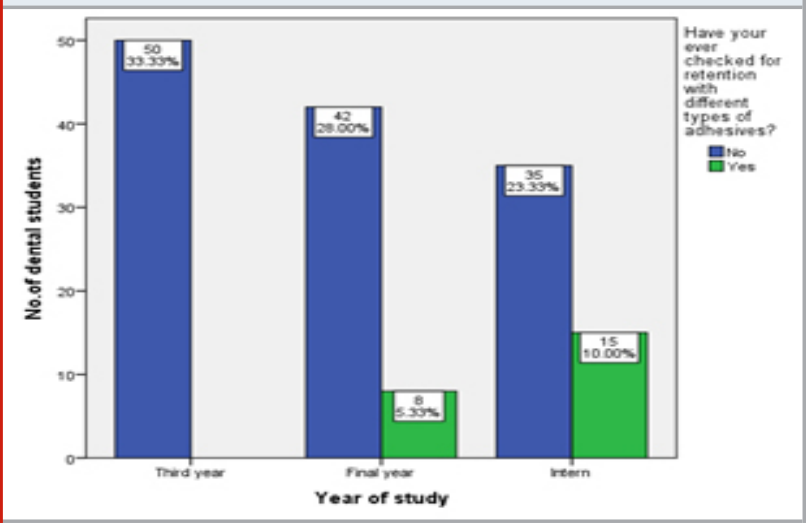

CONCLUSION

Within the limitations of the study, it has been studied that most of the undergraduate dental students were aware of the denture adhesives that are being used although majority of the students were not aware of the different types or application modes of denture adhesives. While denture adhesives are not intended to be an enhancer for ill-fitting dentures, its use largely impacts the comfort level of the patient. Denture adhesive in powder form was the most commonly used and operators felt in both arches use of denture adhesives increases denture retention qualities. Further clinical studies can be done to know the dentist or user experience with different forms of denture adhesives.

\section{REFERENCES}

Ahlawat, P. et al. (2012) 'Survey on availability and usage of denture adhesives in Malaysia: A preliminary study', Asian Journal of Pharmaceutical and Health Sciences, 2(1). Available at: http://www.ajphs.com/ article/2012/2/1/286-289.

Anbu, R. T. et al. (2019) 'Comparison of the Efficacy of Three Different Bone Regeneration Materials: An Animal Study', European journal of dentistry, 13(1), pp. 22-28.

Ariga, P. et al. (2018) 'Determination of Correlation of Width of Maxillary Anterior Teeth using Extraoral and Intraoral Factors in Indian Population: A Systematic Review', World Journal of Dentistry, 9(1), pp. 68-75.

Ashok, V. and Ganapathy, D. (2019) 'A geometrical method to classify face forms', Journal of oral biology and craniofacial research, 9(3), pp. 232-235.

Bo, T. M. et al. (no date) 'Utilization of Denture Adhesives and the Factors Associated with its Use: A CrossSectional Survey'. doi: 10.21203/rs.2.21546/v1.

Coates, A. J. (2000) 'Usage of denture adhesives', Journal of dentistry, 28(2), pp. 137-140.

Duraisamy, R. et al. (2019) 'Compatibility of Nonoriginal Abutments With Implants: Evaluation of Microgap at the Implant-Abutment Interface, With Original and Nonoriginal Abutments', Implant dentistry, 28(3), pp. 289-295.

Evaluation of Corrosive Behavior of Four Nickelchromium Alloys in Artificial Saliva by Cyclic Polarization Test:An in vitro Study' (2017) World Journal of Dentistry, 8(6), pp. 477-482.

Fakhri, H. et al. (2009) 'The knowledge and attitude of general dentists toward denture adhesives in Tehran', Indian journal of dental research: official publication of Indian Society for Dental Research, 20(2), pp. 164-168.

Figueiral, M. H. et al. (2011) 'The effect of different adhesive materials on retention of maxillary complete dentures', The International journal of prosthodontics, 24(2), pp. 175-177.

Ganapathy, D. M., Kannan, A. and Venugopalan, S. (2017) 'Effect of Coated Surfaces influencing Screw Loosening in Implants: A Systematic Review and Meta-analysis', World Journal of Dentistry, 8(6), pp. 496-502.

Gonçalves, T. M. S. V. et al. (2014) 'Denture adhesives improve mastication in denture wearers', The 
International journal of prosthodontics, 27(2), pp. 140-146.

Grasso, J. E. (2004) 'Denture adhesives', Dental clinics of North America, 48(3), pp. 721-33, vii.

Gupta, P., Ariga, P. and Deogade, S. C. (2018) 'Effect of Monopoly-coating Agent on the Surface Roughness of a Tissue Conditioner Subjected to Cleansing and Disinfection: A Contact Profilometric Study', Contemporary clinical dentistry, 9(Suppl 1), pp. S122S126.

Jain, A. R. (2017a) 'Clinical and Functional Outcomes of Implant Prostheses in Fibula Free Flaps', World Journal of Dentistry, 8(3), pp. 171-176.

Jain, A. R. (2017b) 'Prevalence of Partial Edentulousness and Treatment needs in Rural Population of South India', World Journal of Dentistry, 8(3), pp. 213-217.

Karlsson, S. and Swartz, B. (1981) 'Denture adhesives - their effect on the mobility of full upper dentures during chewing. A cineradiographic study', Swedish dental journal, 5(5-6), pp. 207-211.

Mantri, S. et al. (2014) 'Knowledge, Attitude and Practices of Denture Adhesives Use Among Private Dental Practitioners' of Jabalpur City, Madhya Pradesh: A Cross Sectional Survey', The Journal of Indian Prosthodontic Society, pp. 243-250. doi: 10.1007/ s13191-013-0318-y.

Muneer, M. U., Ahmed, A. R. and Kamran, M. F. (2013) 'AWARENESS OF DENTISTS AND COMPLETE DENTURE WEARERS TOWARDS DENTURE ADHESIVES', Pakistan Oral \& Dental Journal, 33(1). Available at: https://bit. ly/3fumrYo
Musani, S., Dugal, R. and Kothavade, M. (2010) 'A review of denture adhesives used in the dental profession', Annals and essences of dentistry, 2(3), pp. 129-133. Neill, D. J. and Roberts, B. J. (1973) 'The effect of denture fixatives on masticatory performance in complete denture patients', Journal of dentistry, 1(5), pp. 219-222.

Polyzois, G. et al. (2017) 'Attitudes of dentists toward denture adhesives: A questionnaire survey in Greece', The Journal of prosthetic dentistry, 118(5), pp. 643649.

Ranganathan, H., Ganapathy, D. M. and Jain, A. R. (2017) 'Cervical and Incisal Marginal Discrepancy in Ceramic Laminate Veneering Materials: A SEM Analysis', Contemporary clinical dentistry, 8(2), pp. 272-278.

Shah, H. (2012) 'Prosthetic rehabilitation part II: technical procedures', British dental journal, 212(10), pp. 512-512.

Shah, R. J. et al. (2015) 'Knowledge and attitude towards denture adhesives: A survey on dentists and complete denture wearers', Int J Prosthodont Restor Dent, 5(3), pp. 74-80.

Temel, K. (2007) '“A survey of dentists” attitudes toward Denture Adhesives".' OHDMBSC.

Varghese, S. S., Ramesh, A. and Veeraiyan, D. N. (2019) 'Blended Module-Based Teaching in Biostatistics and Research Methodology: A Retrospective Study with Postgraduate Dental Students', Journal of dental education, 83(4), pp. 445-450. 